\title{
Aile Uyum Ölçeği'nin Türkçe Formunun Psikometrik Özellikleri
}

\author{
Müge DUMAN KULA, Halil EKŞi, ibrahim DEMiRCi*
}

Aile Uyum Ölçeği'nin Türkçe Formunun Psikometrik Özellikleri

Özet

$\mathrm{Bu}$ çalışmanın amacı Aile Uyum Ölçeği'nin kısa formunu Türkçeye uyarlamak ve ölçeğin psikometrik özelliklerini incelemektir. Çalışma grubunda 483 katııımc bulunmaktadır. Doğrulayıcı faktör analizinde tek boyutlu yapı iyi uyum göstermiştir. Madde faktör yükleri .70 ile .89 arasında değişiklik göstermektedir. İç tutarlıık güvenirlik katsayısı .91 bulunmuştur. Aile Uyum Ölçeği'nin madde toplam korelasyon katsayıları 68 ile .84 arasında değişmektedir. Aile Uyum Ölçeği'nin yaşam doyumu ve öznel mutluluk ile gösterdiği pozitif ilişkiye göre ölçeğin kabul edilir ölçüt bağıntılı geçerliğe sahip olduğu söylenebilir. Araştırmanın sonuçları doğrultusunda Aile Uyum Ölçeği'nin Türkçe formunun geçerlik ve güvenirlik özellikleri ölçeğin Türkiye'de yapılacak bilimsel çalışmalarda kullanılabileceğini göstermektedir.

Anahtar Kelimeler: Aile Uyumu, Doğrulayıcı Faktör Analizi, Geçerlik, Güvenirlik
The Psychometric Properties of the Turkish form of Family Harmony Scale

Abstract

The purpose of this study was to adapt the short form of the Family Harmony Scale to Turkish and examined the psychometric properties of the scale. The study group consists of 483 participants. In the confirmatory factor analysis, the onedimensional model fitted the data acceptable. Factor loadings of the items ranged between .70 and .89. The internal consistency reliability coefficient of the scale was .91 . The item total score correlation coefficients of the scale were found to range between .68 and .84 . Positive correlations between the Family Harmony Scale and life satisfaction and subjective happiness showed that the criterion-validity of the scale was acceptable. The validity and reliability characteristics of the Turkish version of the Family Harmony Scale indicate that it can be used in scientific research conducted in Turkey.

Key Words: Family Harmony, Confirmatory Factor Analysis, Validity, Reliability

\section{Giriş}

Aile toplumun en küçük yapı taşıdır. Bu sebeple toplumda herhangi bir ortamda karşılaşılan çocuk, genç veya yaşı bir bireye "Aile ne demek?" diye sorulduğunda yanıt almamak gibi bir durum söz konusu değildir. Herkesin aile ile ilgili söyleyebileceği, betimleyeceği şeyler vardır. Fakat

* Müge DUMAN KULA, Yük.Lis.Öğr., Marmara Üniversitesi, Rehberlik ve Psikolojik Danışmanlık Anabilim Dalı, mugeduman92@gmail.com, ORCID ID orcid.org / 0000-0003-2955-4771, Halil EKŞi; Prof.Dr., Marmara Üniversitesi, Eğitim Bilimleri Bölümü, h.eksi70@gmail.com, ORCID ID orcid.org / 0000-0001-7520-4559; Ibrahim DEMiRCi, Dr.Öğr.Üyesi., Sinop Üniversitesi, Eğitim Bilimleri Bölümü, ibrahimdemircipdr@gmail.com, ORCID ID orcid.org / 00000002-4143-3916 
Müge DUMAN KULA | Halil EKŞi | ibrahim DEMIRCi

toplumların zaman içinde değişimlere uğraması ve kültürlerarası farklılıklar ailenin evrensel anlamda tanımının yapılmasına da engel olmuştur. Toplumlar için bu derece öneme sahip olan ailenin en değerli öznelerinden birisi ise yakın, benzer, iş birliği ve karşııkılı ilişkilerinde vurgulandığı aile uyumudur. Bunun kişilerin zihinsel sağlıkları ve toplumların refahı için gerekli olduğu düşünülmektedir (Ip, 2003; Kavikondala ve ark. 2015). Ailedeki uyum ya da uyumsuzluk, her üyeyi kişisel olarak ilgilendirdiğinden toplumsal huzurun sağlanması için üyelerin bireysel çabası önem taşımaktadır.

Toplumsal sistem için önemli yapıda olan aile, bu sistemin özelliklerini yansıtma ve aileyi oluşturan bireylere bunu aktarma görevine sahiptir. Bu bağlamda Türk kültüründe aile kurumu oldukça önemlidir. Yaşanan değişimlere rağmen aile gücünü korumaktadır. Eski Türklerde aile kavramı bugünkünden pek farklı değildir. Aileye verilen önem ve ailenin fonksiyonları dönemin toplumsal yapısına bağlı olarak şekil almasına rağmen İslamiyet ile birlikte aile yapısında ve ahlak sisteminde değişimler olmuştur. İslam kültürü, aile üyelerinin birbirine karşı hak ve yükümlülüklerini yeniden belirlemiştir. Türk aile yapısının oluşumunda İslamiyet'in yanında gelenekler, toprak sistemi, coğrafi koşullar ve yönetim sistemi gibi faktörlerin de etkisi bulunmaktadır (Doğan, 2009). Türk aile yapısında modernleşme süreci ise Cumhuriyetin ilanı sonrasında medeni kanunda yapılan değişikliklerle kadın ve erkeğin haklarının korunması ve rollerin değişimiyle gerçekleştirilmeye çalışılmıştır (Çelik, 2000).

Kültürler bireyci ve toplulukçu olarak ayrıldıklarından (Markus ve Kitiyama, 1991) bu yapının parçası olan aile yapıları ve ilişkileri de ona göre değişiklik göstermektedir (Yıldııı, 2013). Bu değişiklikler Doğu ve Batı kültürünün hâkim olduğu ailelerin farklı yapılarda olmasına sebep olmuştur. Aile kurmanın ilk adımı olan evliliğin başlangıç aşaması eş seçme sürecinden evliliğin sona ermesine kadar olan tüm süreci kültürel farklılılar etkilemektedir. Doğu kültüründe eş seçimini aile ve akrabalar etkileyerek eş adayının ailenin onayından geçmesi ve aile için gerekli kriterlere sahip olması önemlidir. Batı kültüründe ise kişinin kendi kararı ve kriterleriyle eşini seçmesi, bağımsızlık ve olgunluğun işaretidir (Peseschkian, 1999). Buradan da anlaşılacağı üzere bireyciliğin hâkim olduğu batı kültürüne sahip aile de "ben" bilinci gelişmiştir. Bireyler ilgilerini kendilerine yönelttiklerinden sağııklı aile kurmaları zorlaşmakta ve aile hayatı için öldürücü virüs niteliği taşıyan kişinin kendisini mükemmel görmesi, hatalarını kabul etmemesi, affetmemesi ve özür dilememesi gibi davranışların yaşanılması kaçınılmaz hale gelmektedir (Çayıroğlu, 2016). Toplulukçu kültürde ise "biz" bilinci gelişmiş ve bu nedenle de duygusal bağılığın katkısıyla aileyle geçen zaman artmıştır (Kağıtçıbaşı, 2000). Türk kültürü bireycilik ve toplulukçuluk bakış açısıyla değerlendirildiğinde aile, akraba ve sosyal bağların güçlü olduğundan yola çıkarak genel olarak toplulukçu bir toplum olarak sınıflandırılmıştır (Hofstede, 2001). Ancak özellikle eğitim düzeyi yüksek gruplarda bireycilik özelliklerinin giderek arttığı vurgulanmaktadır (İmamoğlu ve Karakitapoğlu-Aygün, 2004). Türk toplumundaki yapısal değişimlerin, içinde yaşayan bireylerin toplulukçu ya da bireyci özelliklere sahip olup olmamasını da etkileyeceği düşünülmektedir.

Modernleşen kültüründe etkisiyle aile içinde çeşitli sorunlar yaşanmaya başlamıştır. Ünlü'ye (2013) göre bu sorunlar temel güdülerin doyurulması, aile içi ilişkiler ve etkileşim, gelirin yönetimi 
ve tüketim, sosyal etkinlikler ve ilişkiler ve çocukların bakım ve eğitimi şeklinde sınıflandırılmaktadır. Farklı bir sınıflandırma ise aile içi iletişim ve etkileşim problemleri, ailede yaşanan kuşak çatışmaları, ekonomik kökenli sorunlar ve aile içi şiddettir. Bu problemlerin çözümlenememesi sonucunda boşanma gerçekleşerek evlilik son bulur. Bu durumun yaşanmaması için eşlerin birbirine karşı anlayışlı ve fedakârca davranışlar sergilemeleri gerekmektedir. Eşlerin birbirinden farklı kişilik yapılarına sahip olmasına rağmen iyi ilişkiler geliştirmesinin sonucunda çözülemeyecek problemleri bulunmamaktadır (Durğun, 2016). Buna karşın güçlü ailelerdeki bireyler birbirleriyle ilgilenerek sevgilerini ifade ederler. Zaman ve enerjilerinin büyük çoğunluğunu aile faaliyetlerine yatırmakta, sorunlarına birlikte çözüm yolu aramakta ve birbirlerinin görüşlerini dinlemektedirler (DeFrain ve Asay, 2007). Aile içindeki ilişkinin niteliği aile uyumunu etkilemektedir. Toplum içinde birbirinden farklı aile yapıları olmasına rağmen ilişki yönetimi güçlü olan ailelerin uyumlu davranışlar sergilemesi daha olasıdır.

Bireyci kültürlerde ailenin desteği daha önemliyken toplulukçu kültürlerde ailenin uyumu önemlidir. Bireyci kültürlerde bireysel arzular ön plandadır, ailenin ortak düşünceleri önemsenmeksizin duygular ifade edilir. Toplulukçu kültürlerde aile üyeleri aileye karşı sorumludur. Ebeveynlerinin önemli kararları aile üyeleri tarafından hayatları boyunca büyük önem taşır. Aile üyeleri duygularını aileyi ifade edemeyebilir. Çünkü bu durum ailenin uyumunun bozulmasına sebep olabilir (Oyserman, Coon, \& Kemmelmeier, 2002). Bu bağlamda toplulukçu kültürlerde ailenin uyumunu sağlamak için bireysel istekler ve ihtiyaçlar ertelenebilir. Çünkü kişi kendini ailesiyle tanımlıyor olabilir. Öte yandan ailenin uyumunun kişinin bireysel iyi oluşu için de etkili bir role sahip olduğu söylenebilir. Aile uyumunun kişinin iyi oluşu ile ilişkisini incelemek aile danışmanlığı çalışmaları için faydalı olabilir.

Eşler arasında karşılıklı sevgi ve saygı, ilişkileri hakkında farkındalık, duygu ve düşüncelerini rahatça ifade etme, birbirlerini dinleme evlilik uyumunun olmazsa olmazlarıdır (Demir, 2016). Bunun sonucunda yaşanan mutluluk ve memnuniyette evlilik uyumunun gücünü gösterir (Akar, 2005). Evlilik uyumu pozitif psikolojinin amacına bu nokta da katkı sağlamaktadır. Çünkü pozitif psikoloji insanların yaşamlarındaki anlam ve mutluluk arayışında onlara yardımcı olur (Haidt, 2013). Bu arayış esnasında en çok sorgulanması, incelenmesi gereken faktörlerin başında aile gelir. Ailedeki bireylerin etkileşimleri, ailenin uyumu bireyin günlük yaşantısını doğrudan etkiler. Uyumlu olan ailelerde ortak değer ve amaçlar vardır. Tüm üyeler rollerine uygun davranarak herhangi bir konuda görüş farklılığı yaşadıklarında çözüme ulaşmak için iş birliği yaparlar. Süreç içinde kırıcı olmak yerine yapıcılığı tercih ederek ailelerinin güçlü kalmasını sağlarlar (Ackerman, 2017). Sadece bozulan, iyi gitmeyen yönleri ile değil aynı zamanda işleyen ve korunması gereken yönleriyle de ilgilenilmesi gerektiğini savunan pozitif psikoloji kapsamında aile uyumu, üyelerin öznel mutluluk algıları ve yaşam doyumları ile etkileşim içindedir. Bu düşünceden hareketle bu çalışmada aile uyumunu ölçmek amacıyla geliştirilmiş olan bir ölçüm aracının Türkçeye uyarlanması ve bu yolla insanoğlu için çocukluktan yaşılığa kadar attığı her adımda önemli olan evlilik ve aile hayatıyla ilgili çalışmalarda kullanılabilecek yeni bir ölçüm aracının Türkçe literatüre kazandırılması amaçlanmaktadır. 
Müge DUMAN KULA | Halil EKŞi | ibrahim DEMIRCi

Türkiye'de aile ilişkilerinin dinamiklerini araştıran çeşitli çalışmalar yapılmaktadır. Bu bağlamda aile uyumunu değerlendirecek bir ölçme aracı bilimsel araştırmaların yapılmasına katkı sağlayabilir.

\section{Yöntem}

\section{1. Çalışma Grubu}

Araştırmanın çalışma grubu Marmara Üniversitesi'nin eğitim fakültesinde öğrenim gören 210 öğrenci $(\% 43,5)$ çalışan ve halk grubundan $273(\% 56,5)$ olmak üzere toplan 483 katılımcıdan oluşmaktadır. Araştırmaya katılan 359'u kadın (\%74.3) 122'si erkek (\%25.3) katıımcının yaşları 17 ile 62 arasında değişmekte ve yaş ortalamaları 26.94 ( \pm 8,24) olarak hesaplanmıştır. Katılımcıların 399'u (\%82.6) çekirdek aileden, 81'i (\% 16.8) ise geniş aileden geldiğini ifade etmiştir.

Uyum geçerliği için çalışma grubu Marmara Üniversitesi'nin eğitim fakültesinde öğrenim gören 65 öğrenci $(\% 45,8)$ çalışan ve halk grubundan $77(\% 44,2)$ olmak üzere toplan 142 katılımcıdan oluşmaktadır. Araştırmaya katılan 107'i kadın (\%75) 35'si erkek (\%25) katılımcının yaşları 18 ile 56 arasında değişmekte ve yaş ortalamaları 23.25 ( \pm 4.65$)$ olarak hesaplanmıştır.

\subsection{Veri Toplama Araçları}

Aile Uyumu Ölçeği: "Aile Uyumu Ölçeği” toplumun refahında pozitif aile ilişkilerinin rolünü ortaya koymak ve bu doğrultuda aile uyumunu ölçmek amacıyla Kavikondala ve çalışma arkadaşları (2015) tarafından Türk toplumu gibi genel olarak toplulukçu kültür yapısını benimsemiş Çin toplumunu esas alarak geliştirilmiş bir ölçüm aracıdır. 24 maddelik uzun formu ve 5 maddelik kısa formu bulunmaktadır. Aile Uyum Ölçeğinin orijinal halinin geliştirilme sürecinde yapı geçerliğini ortaya koymak amacıyla doğrulayıcı faktör analizi yapıımıştır. Faktör analizi sonucunda ölçeğin kısa formunun tek faktörlü olduğu ve iyi uyum gösterdiği belirlenmiştir. Ölçeğin Cronbach alfa güvenirlik katsayısı ise .92 olarak bulunmuştur.

Aile Uyum Ölçeği'nin uyum geçerliğini değerlendirmek amacıyla depresyon, stresli yaşam olayları, aile işlevselliği, aile ile geçirilen boş zaman, öznel mutluluk, fiziksel sağlığa ilişkin yaşam kalitesi ve fiziksel sağlığa ilişkin yaşam kalitesi arasındaki ilişkiye bakılmıştır. Ölçeğin depresyon ( $r=-$ .24) ve stresli yaşam olayları ( $r=-.13$ ) ile negatif, aile işlevselliği $(r=.49)$, aile ile geçirilen boş zaman $(r=.29)$, öznel mutluluk ( $r=.33)$, fiziksel sağlığa ilişkin yaşam kalitesi $(r=.13)$ ve fiziksel sağlığa ilişkin yaşam kalitesi ( $r=.21$ ) ile pozitif ilişki gösterdiği bulunmuştur (Kavikondala ve ark., 2015).

Ölçeğin Puanlanması ve Değerlendirilmesi: Ölçekte alınan puanlar yükseldikçe aile uyumu yükselmektedir. Ölçeğin Türkçe Formunun puanlanması $5^{\prime}$ li (1= Kesinlikle katılmıyorum, 5= Kesinlikle Katılıyorum) bir derecelendirme sistemine göre yapılmaktadır. Ölçek sonucunda toplam puan aralığı 5 ile 25 arasında değişiklik göstermektedir. Ölçekte ters kodlanan madde bulunmamaktadır.

Yaşam Doyumu Ölçeği: Diener, Emmons, Laresen ve Griffin (1985) tarafından geliştirilmiştir. Kişinin öz-bildirim yoluyla cevapladığı bu ölçek yaşamdan aldığı doyumu ölçmeyi amaçlamıştır. Tek boyutlu yapı sergileyen ölçeğin 5 maddesi bulunmaktadır. Puanlaması 7’li Likert tipi derecelendir- 
me sistemiyle yapılmaktadır. Durak, Senol-Durak ve Gencoz (2010) tarafından Türkçeye uyarlanan Yaşam Doyumu Ölçeği'nin Türk üniversite öğrencilerinden elde edilen veriler üzerinde uygulanan doğrulayıc faktör analizinde tek boyutlu yapısının kabul edilebilir uyum verdiği görülmüştür. Ölçeğin iç tutarlılığı 81 olarak hesaplanmıştır. Ölçekteki maddelere ait madde toplam test korelasyonlarının .55 ile .63 arasında değiştiği bulunmuştur.

Öznel Mutluluk Ölçeği: Lyubomirsky ve Lepper (1999) tarafından geliştirilen ölçek Doğan ve Totan, (2013) tarafından Türkçeye uyarlanmıştır. Tek boyutlu bir yapıya sahip olmakla birlikte 4 maddeden oluşmaktadır. Puanlanması 7'li Likert tipi bir derecelendirme sistemine göre yapılmaktadır. Ölçeğin psikometrik özellikleri incelenirken açımlayıcı ve doğrulayıc faktör analizi, iç tutarlık ve ölçüt bağıntılı geçerlik yöntemleri kullanılmıştır. Cronbach alfa iç tutarlılık güvenirlik katsayısı üniversite grubunda .70, halk grubunda .65 olarak bulunmuştur. Öznel Mutluluk Ölçeği, Yaşam Doyumu Ölçeği, Oxford Mutluluk Ölçeği Yaşam Yönelimi Ölçeği ile pozitif ilişki göstermiştir.

\section{3. İzin ve Çeviri Süreci}

Aile Uyumu Ölçeğinin Türkçeye uyarlama çalışması için ölçeği geliştiren çalışma grubu "FAMILY Cohort teame" mail yoluyla ulaşılmış ve ölçeğin uyarlama yapılması için gerekli izin alınmıştır. Aile Uyumu Ölçeğinin Türkçeye çevrilme sürecinde çeviri-tekrar çeviri yöntemi kullanılmıştır. Öncelikle ölçeğin Türkçeye çevirisi 5 uzman tarafından yapılmıştır. Ardından Eğitim Bilimleri alanından dört uzman ölçeğin orijinal ve çeviri formu üzerinde gerekli çalışmaları yaparak Türkçe formunun oluşumunu sağlamıştır. Bu form, uzman paneli oluşturularak 5 uzman tarafından incelenmiştir. Oluşturulan son form Aile ve evlilik terapisi konusunda uzman bir akadamisyen tarafından incelenerek Türk aile yapısına uygunluğu değerlendirilmiştir. Son olarak bir bağımsız uzman ölçeği Türkçeden İngilizceye geri çevirmiştir. Bağımsız bir uzmanın ölçeği Türkçeden İngilizceye geri çevirmesinin ardından elde edilen İngilizce formu inceleyen "FAMILY Cohort team" geri çeviri için onay verdikten sonra Türkçe forma son şekli verilerek uygulamaya geçilmiştir.

\subsection{Verilerin Çözümlenmesi}

Aile Uyumu Ölçeğinin psikometrik özelliklerinin incelenirken yapı geçerliği çalışmasında doğrulayıcı faktör analizi kullanıımıştır. Doğrulayıcı faktör analizinde daha önceden belirlenen bir kuramsal yapı doğrultusunda geliştirilen ölçme aracından elde edilen verilere dayanarak, söz konusu yapının doğrulanıp doğrulanmadığı test edilmeye çalışımaktadır (Çokluk, Şekercioğlu ve Büyüköztürk, 2010). Bu nedenle Aile Uyumu Ölçeğinin uyarlama çalışmasında doğrulayıcı faktör analizi tercih edilmiştir.

Doğrulayıcı faktör analizinde test edilen modelin uyum iyiliğini belirlemek için Ki-Kare Uyum Testi (Chi-Square Goodness), Karşılaştırmalı Uyum İndeksi (CFI), Normlaştırılmış Uyum İndeksi (NFI), Normlaştırımamış Uyum İndeksi (NNFI), Standartlaştılmış Ortalama Hataların Karekökü (SRMR) ve Yaklaşık Hataların Ortalama Karekökü’dür (RMSEA) kullanılmıştır. RMSEA ve SRMR değerleri için kabul edilebilir uyum değeri .08 (Brown ve Cudeck, 1993; Byrne ve Campbell, 1999), CFI, NFI ve NNFI indeksleri için kabul edilebilir uyum değeri .90 (Bentler, 1980; Bentler ve Bonett, 
1980; Schermelleh-Engel ve Moosbrugger, 2003), $x^{2} /$ sd kabul edilebilir değerinin ise 3 'ün altı (Schermelleh-Engel ve Moosbrugger, 2003) olduğu ifade edilmektedir.

Ölçeğin güvenirliği için iç tutarlık katsayısı hesaplanmıştır. Madde analizi ise düzeltilmiş maddetoplam puan korelasyonu ile incelenmiştir.

\section{Bulgular}

\subsection{Yapı Geçerliği}

Aile Uyum Ölçeği'nin orijinal halinin tek boyutlu yapısını incelemek için doğrulayıcı faktör analizi yapılmıştır. Bu formdaki 5 maddeli ve tek boyutlu yapının Türkçe formuna ilişkin uyum indeksi kabul edilebilirdir. $\left(\chi_{(5, \mathrm{~N}=483)}^{2}=17,739, \mathrm{p}<.05 ; \mathrm{CFI}=.99 ; \mathrm{TLI}=.99 ;\right.$ SRMR = .016; RMSEA = .073). Ölçeğin maddelerin yol katsayıları faktör yükleri .70 ile .89 arasında değişmektedir. Ölçeğin doğrulayıcı faktör analizi sonuçları Tablo 1'de gösterilmektedir.

Tablo 1. Aile Uyumu Ölçeğinin DFA Sonuçları

\begin{tabular}{lcccc}
\hline \hline Madde No & $\lambda$ & $\vartheta$ & $t$ & $R^{2}$ \\
\hline Madde 1 & 0,77 & .40 & 13,568 & 0,60 \\
Madde 2 & 0,89 & .20 & 10,223 & 0,80 \\
Madde 3 & 0,86 & .25 & 11,559 & 0,75 \\
Madde 4 & 0,70 & .51 & 14,255 & 0,49 \\
Madde 5 & 0,86 & .27 & 11,844 & 0,73 \\
\hline
\end{tabular}

$\lambda=$ Standardize edilmiş faktör yükleri; $\theta=$ hata varyansı

\section{2. Ölçüt Bağıntılı Geçerlik}

Aile Uyumu Ölçeğinin ölçüt-bağıntılı geçerliğini değerlendirmek için Yaşam Doyumu Ölçeği ve Öznel Mutluluk Ölçeği ile olan ilişkisi incelenmiştir. Ölçekler ve alt boyutlar arasındaki ilişkilere ait bulgular Tablo 2'de gösterilmiştir.

Tablo 2. Aile Uyumu Ölçeğinin ile Yaşam Doyumu ve Öznel Mutluluk Düzeyleri Arasındaki ilişkilere Yönelik Bulgular

\begin{tabular}{lccc}
\hline \hline Ölçekler & 1 & 2 & 3 \\
\hline 1. Aile Uyumu & - & & \\
2. Öznel Mutluluk &, $445^{* *}$ & - & \\
3. Yaşam Doyumu &, $471^{* *}$ &, $608^{* *}$ & - \\
Ortalama & 19,83 & 21,31 & 18,35 \\
Standart Sapma & 4,44 & 7,23 & 4,43 \\
\hline
\end{tabular}


$\mathrm{N}=142, * * \mathrm{p}<0.01$

Tablo 2'de görüldüğü üzere Aile Uyumu Ölçeği yaşam doyumu (.45) ve öznel mutluluk (.47) ile pozitif ilişkili bulunmuştur.

\subsection{Madde Analizi ve Güvenirlik}

Ölçek maddelerinin toplam puanı yordama gücünü ve ayırt ediciliğini belirlemek üzere madde analizi yapıımıştır. Ölçekteki maddelerin düzeltilmiş madde toplam puan korelasyonları .68 ile .84, arasında değişmektedir. Aile Uyumu Ölçeği'nin Cronbach alpha iç tutarlılık katsayısı .91 olarak hesaplanmıştır. Bulgular Tablo 3'de verilmiştir.

Tablo 3. Aile Uyum Ölçeği'nin Düzeltilmiş Madde Toplam Test Korelasyonları ve Betimsel İstatistikler

\begin{tabular}{cccccccc}
\hline \hline Madde No & En Düşük & En Yüksek & $\bar{X}$ & Ss & Basıklık & Çarpıklık & DMTTK \\
\hline 1 & 1,00 & 5,00 & 3,98 & 1,06 & $-0,98$ & 0,39 & 0,74 \\
2 & 1,00 & 5,00 & 4,02 & 0,94 & $-1,00$ & 0,77 & 0,84 \\
3 & 1,00 & 5,00 & 4,05 & 0,92 & $-0,81$ & 0,28 & 0,81 \\
4 & 2,00 & 5,00 & 4,50 & 0,73 & $-1,34$ & 1,09 & 0,68 \\
5 & 1,00 & 5,00 & 4,13 & 0,95 & $-1,19$ & 1,21 & 0,81 \\
\hline
\end{tabular}

*DMTTK: Düzeltilmiş Madde Toplam Test Korelasyonları

\section{Tartışma}

Bu çalışmanın amacı, Kavikondala ve arkadaşları (2015) aile uyumunu ölçmek amacıyla geliştirmiş olduğu 5 maddelik kısa formlu ölçüm aracının Türkçeye uyarlanması ve Türk kültüründe sınanmasıdır. Bu amaçla ölçeği geliştiren çalışma grubunun isteklerine uygun olarak çeviri ve geri çeviri çalışmaları yapılmıştır. Ölçeğin önce 5 uzman aracılığıyla Türkçeye çevirisi yapılmış; ardından Eğitim Bilimleri alanından dört çalışmacı tarafından İngilizce ve Türkçe formlara dair istişare edip ifadeleri semantik ve sentaks açıdan incelemiştir. Yapılması gereken düzeltmelerin ardından oluşturulan Türkçe form aile ve evlilik terapisi konusunda uzman bir akademisyen tarafından incelenerek Türk aile yapısına uygunluğu değerlendirilmiştir. Bağımsız bir uzmanın ölçeği Türkçeden İngilizceye geri çevirmesinin ardından elde edilen İngilizce formu inceleyen "FAMILY Cohort team" geri çeviri için onay verdikten sonra Türkçe forma son şekli verilerek uygulamaya geçilmiştir.

Yapı geçerliliği değerlendirilirken ölçeğin orijinal formunda bulunan tek boyutlu yapının test edilmesine yönelik doğrulayıcı faktör analizi yapılmıştır. Bu analizde test edilen modelin uyum gösterme durumunu değerlendirmek amacıyla ölçeğin uyum indekslerinin sonuçları uyum indeksleri kabul edilebilir kriterleriyle incelenmiştir. Uyum indekslerinin kabul edilebilir düzeyde olduğu sonucuna varıımıştır. Bu sonuçlar ise ölçme aracının tek faktörlü yapısının bu çalışma grubu içinde geçerlilik gösterdiğini ispatlamıştır. 
Ölçüt geçerliği çalışmasında aile uyumu ile yaşam doyumu ve öznel mutluluk arasındaki ilişkiler ele alınmıştır. Aile uyumu, yaşam doyumu ve öznel mutluluk ile pozitif ilişkili bulunmuştur. Bu sonuçlara göre aile uyumu arttıkça bireylerin yaşam doyumu ve öznel mutlulukları da artmaktadır. Ölçeğin orijinal formunun geçerlilik çalışmalarında da öznel mutlulukla olan ilişkisi pozitif düzeyde anlamlı çıkmıştır (Kavikondala ve ark., 2015). Araştırmadan önce beklenildiği gibi aile uyumu, kişinin yaşamından memnun olması ve mutlu hissetmesi ile pozitif ilişkili bulunmuştur.

Güvenirliğe dair yapılan çalışmalar kapsamında iç tutarlıı̆ına bakılmıştır. Cronbach alpha iç tutarlık katsayısının .70'in üzerinde olması ölçeğin güvenilir olduğunu göstermektedir (Özgüven, 1994). Uyarlanan Aile Uyum Ölçeği'nin iç tutarlıık katsayısı .91 olduğundan ölçek güvenilirdir. Ayrıca ölçeğin düzeltilmiş madde toplam puan korelasyonlarının .30'un üzerinde olması ölçekteki maddelerin benzer özellikteki yapıya yönelik olduğunu göstermektedir (Büyüköztürk, 2011).

Bu araştırmanın bazı sınılıııkları bulunmaktadır. İlk olarak ölçeğin ölçüt bağıntılı geçerliği saptamak amacıyla mutluluk ve yaşam doyumu arasındaki ilişkileri incelenmiştir. Buna ek olarak aile uyumun göstergeleri olarak kabul edilebilecek olan evlilik uyumu ve evlilik doyumu gibi kavramlarla ilişkisinin incelenmesi faydalı olabilir. Ayrıca evli, boşanmış ve bekâr bireyler arasında aile uyumu açısından farklılık olup olmadığı incelenebilir. Ölçeğin güvenirliğini incelemek için iç tutarlık yöntemi kullanılmıştır. Buna ek olarak zaman karşı değişmezliği için kanıt sağlamak amacıyla test tekrar test yöntemi kullanılabilir. Ayrıca ölçek uyarlama çalışmalarına başlamadan önce uyarlanacak ölçeğin hangi ihtiyacı karşılayacağı belirlenmelidir. Ölçek uyarlama sürecinde çeviriden kaynaklı ya da kültürel farklılıklardan kaynaklı problemler çıkabilir. Bu nedenle öncelikle kültürel olarak uyumlu olacağı düşünülen ölçeklerin tercih edilmesi ve çevirinin kültüre uygun bir şekilde gerçekleştirilmesi önemlidir (Güngör, 2016). Özellikle sosyal bilimlerde ölçme araçlarını kullanırken güçlü yanlarına ve zayıf yanlarına dikkat etmek ve teorinin inceliklerini anlamak önemlidir (DeVellis, 2014).

Ölçek uyarlama çalışmalarında yapısal eşitlik modeline dayalı bir yöntem olan doğrulayıcı faktör analizi sıklıkla kullanılmaktadır. DFA'da amaç keşif amaçlı olmaktan ziyade var olan yapının sınanmasıdır. Yapısal eşitlik temelli yaklaşımlar, gerçek verilerin belirtilen modele ne kadar iyi uyduğunu değerlendirmek ve alternatif modellerin test edip karşılaştırmak için istatistiksel bir kriter de sağlayabilmektedir (DeVellis, 2014). Ancak ölçme aracıyla ilgili çalışmaların çeşitlendirilmesi faydalı olacaktır. Nitel çalışmalar ve odak grup çalışmaları bu araştırmada incelenen aile uyumu kavramının Türk kültüründeki yansımasını daha iyi anlamak için kullanılabilir.

Ölçeğin psikometrik özelliklerinin incelenmesi sonucunda elde edilen bulgular Aile Uyum Ölçeği'nin bilimsel çalışmalarda kullanılabileceğini göstermektedir. Ölçeğin yanıtlama süresinin kısa olmasının ve uygulama kolaylığının araştırmalarda kullanıımasına imkân sağlayacağı söylenebilir. Son yıllarda hızla gelişen Aile Eğitimi ve Danışmanlığı alanına farklı bakış açısı getirebileceği düşünülmektedir. Türkçe de evlilik uyumuyla ilgili ölçme araçları bulunsa da uyarlanan ölçeğin kavramsal yapısına benzer bir ölçme aracına rastlanamamıştır. Toplulukçu kültürün özelliklerinden yola çıkarak Aile Uyumu Ölçeğinin Türkiye'de de kullanılabileceği düşünülmüştür. Aile içi iletişim, yetiş- 
kinlikte problem çözme becerisi, evlilik uyumu ve doyumu, aile ve çocuk ilişkilerine dair yapılacak değerlendirme gibi değişkenlerle aile uyumu arasındaki ilişkiler incelenebilir. Ayrıca aile uyumu kişinin yaşamını doğrudan etkilediğinden yaşam doyumu değişkeniyle bağlantılı kapsamlı çalışmalar yapılması önerilmektedir.

\section{Kaynaklar}

Ackerman, N. W. (2017). The family approach to marital disorders. Experimentation and Innovation in Psychotherapy. USA: The Free Press.

Akar, H. (2005). Psikiyatrik yardım talebi olanlar ile yardım talebi olmayan ve boşanma aşamasında olan çiftlerde; çift uyumu ve kişilik özellikleri arasındaki ilişkinin karşılaştııılması. (Uzmanlık Tezi). Bakırköy Prof. Dr. Mazhar Osman Ruh Sağlığı ve Sinir Hastalıkları Eğitim ve Araştırma Hastanesi, İstanbul.

Bentler, P. M. (1980). Multivariate analysis with latent variables: Causal modeling. Annual Review of Psychology, 31(1), 419-456.

Bentler, P. M., \& Bonet, D. G. (1980). Signifcance tests and goodness of fit in the analysis of covariance structures. Psychological Bulletin, 88(3), 588-606.

Brown, M., \& Cudeck, R. (1993). Alternative ways of assessing model fit. In: K. A. Bollen ve J. S. Long (Eds.), Testing structural equation models (s. 136-162). Beverly Hills, CA: Sage.

Bulut, I. (1993). Ruh Hastalığının Aile İşlevlerine Etkisi. Ankara: Başbakanlık Kadın ve Sosyal Hizmetler Müsteşarlığı.

Büyüköztürk, Ş. (2011). Sosyal bilimler için veri analizi el kitabı: İstatistik, araştırma deseni SPSS uygulamaları ve yorum. Ankara: PEGEM A Yayıncilık

Byrne, B. M., \& Campbell, T., L. (1999). Cross-cultural comparisons and the presumption of equivalent measurement and theoretical structure: a look beneath the surface. Journal of Cross-Cultural Psychology, 30(5), 555-574.

Canatan, K. Ve Yıldııım, E. (2013). Aile sosyolojisi. İstanbul: Açıım Yayınevi.

Çayıroğlu, Y. (2016). Modern zamanlarda ailevi çözülmenin psiko-sosyal dinamikleri. Mehir Aile Dergisi, 3(1), $11-40$.

Çelik, C. (2000). Değişim sürecinde Türk aile yapısı ve dini paradigmatik anlam ve işlev farklılaşması. Dergi Karadeniz, 8(8), 25-35.

Çokluk, Ö.,Şekercioğlu, G. ve Büyüköztürk, Ş. (2014). Sosyal Bilimler lç̧in Çok Değişkenli istatistik SPSS ve LISREL Uygulamaları. Ankara: Pegem Akademi Yayıncılık

Demir, D. (2016). Evlilik uyumu ile bağlanma stilleri ve kişilerarası problem çözme davranışı arasındaki ilişkinin incelenmesi (Yüksek lisans tezi). Maltepe Üniversitesi Sosyal Bilimler Enstitüsü, İstanbul. 
DeFrain, J., \& Asay, S. M. (2007). Strong families around the world: An introduction to the family strengths perspective. Marriage \& Family Review, 41(1-2), 1-10.

DeVellis, R. F. (2014). Ölçek geliştirme: Kuram ve uygulamalar. Nobel Akademik Yayıncılık.

Doğan, İ. (2009). Dünden bugüne Türk ailesi. Ankara: Atatürk Kültür Merkezi Yayınları.

Durğun, A. (2016). Aile İçi Problemler ve Çözüm Önerileri. Mehir Aile Dergisi, 3(1), 83- 95.

Güngör, D. (2016). Psikolojide ölçme araçlarının geliştirilmesi ve uyarlanması kılavuzu. Türk psikoloji yazıları, 19, 104-112

Hofstede, G. (2001). Culture's consequences: Comparing values, behaviors, Institutions, organiztions across nations. Thousand Oaks, CA: Sage.

Imamoglu, E. O., \& Karakitapoglu-Aygun, Z. K. (2004). Self-construals and values in different cultural and socioeconomic contexts.Genetic, Social, and General Psychology Monographs, 130(4), 277-306.

Kagıtçıbası, Ç. (2000). Kültürel psikoloji ve kültür bağlamında insan ve aile. İstanbul: Evrim

Kavikondala, S., Stewart, S. M., Ni, M. Y., Chan, B. H., Lee, P. H., Li, K. K., ... \& Lam, W. W. (2016). Structure and validity of Family Harmony Scale: An instrument for measuring harmony. Psychological assessment, 28(3), 307-318.

Markus, H., \& Kitayama, S. (1991). Culture and the self: Implications for cognition, emotion, and motivation. Psychological Review, 98(2), 224-253.

Oyserman, D., Coon, H. M., \& Kemmelmeier, M. (2002). Rethinking individualism and collectivism: Evaluation of theoretical assumptions and meta-analyses. Psychological Bulletin, 128(1), 3-72.

Özgüven, E. (1994). Psikolojik testler. Ankara: Yeni Doğuş Matbaası.

Peseschkian, N. (1999). Pozitif aile terapisi (M. Naim, Çev.) İstanbul: Beyaz.

Schermelleh-Engel, K., \& Moosbrugger, H. (2003). Evaluating the fit of structural equation models: Tests of significance and descriptive goodness-of-fit measures. Methods of Psychological Research Online, 8(2), 23-74.

Ünlü, S. (2013). Aile yapısı ile ilişkileri. Eskişehir: Anadolu Üniversitesi Açıköğretim Fakültesi. 